\title{
WACANA HAK ASASI MANUSIA DALAM FILSAFAT PENDIDIKAN ISLAM DAN BARAT
}

\author{
Lathifatul Izzah \\ Universitas Alma Ata Yogyakarta \\ lathifatul.izzah@almaata.ac.id \\ Peni Catur Renaningtyas \\ Universitas Islam Malang \\ penicaturrenaningtyas21@gmail.com
}

\section{Abstrak}

Hak asasi manusia (HAM) merupakan anugrah Tuhan yang bersifat kodrati. Kesadaran tentang HAM masih belum dipahami secara utuh dan merata di kalangan masyarakat. Padahal sebagai pengetahuan, HAM penting untuk ditransfer ke dalam dunia pendidikan. Dengan demikian, masyarakat dapat mempraktikkan hak yang seharusnya mereka miliki dalam kehidupan bermasyarakat, berbangsa dan bernegara. Artikel ini mengkaji tentang Deklarasi Universal Hak Asasi Manusia (DUHAM) di dunia Barat dan Deklarasi Kairo di dunia Islam sebagai dasar filosofi penegakan hukum atas pelanggaran-pelanggaran hak asasi manusia dalam dunia pendidikan Islam dan Barat. Dalam analisisnya digunakan pendekatan klasik, kultural, dan kritis atau disebut mixed approach. Hasil kajian ini menunjukkan bahwa deklarasi HAM yang dilakukan oleh dunia internasional (PBB) dalam DUHAM dan Deklarasi Kairo oleh OKI, telah memberikan pengetahuan riil tentang pentingnya HAM dalam kehidupan sehingga manusia dapat mengetahui batasan-batasan dan kaidah-kaidah di dalamnya.

Kata Kunci: Hak Asasi Manusia (HAM), Deklarasi Universal Hak Asasi Manusia (DUHAM), Deklarasi Kairo, Filsafat Pendidikan Islam dan Barat. 


\section{Abstract}

Human rights is a natural gift from God. This awareness of human rights has not been understood well and comprehensively by all people. Whereas knowledge, human rights are important to be transformed into the realm of education. Thus, they can exercise the rights they should have in the life of society, nation and state. This article examines the Universal Declaration of Human Rights (UDHR) in the Western world and the Cairo Declaration in the Muslim world as a philosophical basis for upholding the law for human rights violations in the world of Islamic and Western education. The analysis uses classical, cultural, and critical approaches or what is called the mixed approach. The results of this study conclude that the human rights declaration carried out by the international community (UN) in the UDHR and the Cairo Declaration by the OIC has provided real knowledge of human rights in life so that humans can know the limitations and rules in it.

Keywords: Human Rights, Universal Declaration of Human Rights (UDHR), Cairo Declaration, Islamic and Western Education Philosophy.

\section{Pendahuluan}

Filsafat pendidikan adalah cabang dari filsafat yang dikelompokkan secara tematik, yakni filsafat yang mengkaji tentang pendidikan. Subjek sekaligus objek material kajian ilmu pendidikan adalah manusia, peserta didik. ${ }^{1}$ Peserta didik dipandang sebagai individu mandiri, unik, dan mempunyai potensi tersendiri yang dapat berkembang, serta memiliki hak asasi laiknya manusia pada umumnya. Persoalan hak asasi manusia atau HAM senantiasa berhubu-ngan dengan konsep filosofis suatu aliran pemikiran tentang manusia. Di sinilah persoalan antara HAM dan fil-

1 Muhammad Kristiawan, Filsafat Pendidikan: The Choice is Yours (Yogyakarta: Valia Pustaka, 2016), 92. safat pendidikan saling berkelindan. Misalnya, ketika mempersoalkan tentang perintah adil dan persamaan hak alasan diutusnya para nabi dan rasul serta ditetapkannya syariat. Persamaan hak dan keadilan menjadi penghubung prinsip-prinsip menyeluruh dan kaidahkaidah umum untuk menjadi dasar bagi sistem kehidupan yang dapat memelihara eksistensi manusia. ${ }^{2}$

HAM yang bersifat kodrati dan dibawa oleh manusia sejak lahir ke dunia, bahkan di bawah manusia ketika masih berbentuk janin sejatinya merupakan anugerah Tuhan yang Maha Pencipta. Kadang di kalangan masyarakat

\footnotetext{
${ }^{2}$ Farid Abdul Khaliq, Fiqih Politik Islam, trans. by Faturrahman A. Hamid (Jakarta: Amzah, 2005), 221.
} 
luas, kesadaran tentang HAM masih belum dipahami secara merata, dan belum disadari secara semestinya. Hal ini tercermin dari banyaknya pengaduan masyarakat ke komnas HAM, misalnya salah satu kasus tindak pelecehan seksual pada peserta didik. Pelaku umumnya orang-orang di sekitar mereka sendiri, seperti para pendidik atau teman sebayanya atau pihak-pihak lain yang punya kuasa yang seharusnya membimbing dan mengarahkan agar tujuan pendidikan tercapai, tetapi justru anak didik menjadi pelampisan nafsu birahinya. Lebih miris lagi, kadang-kadang pihak-pihak yang melakukan tindakan kekerasan seksual yang jelas-jelas melanggar hak asasi tidak sedikitpun merasa bersalah. Lebih aneh lagi, pelaku pelanggaran jika diingatkan, tidak sedikit yang sadar, meskipun ada juga yang tetap dengan sikap yang acuh tak acuh. ${ }^{3}$

Pembahasan tentang HAM sudah banyak dilakukan oleh para peneliti. Oleh karena itu, artikel ini fokus pada persoalan HAM dalam Filsafat Pendidikan Islam dan Barat, bagaimana Universal Declaration of Human Rights (UDHR) atau Deklarasi Universal HAM (DUHAM) yang dideklarasikan pada 1948 dan Deklarasi Kairo pada 1990 sebagai dasar filosofi penegakan hukum

${ }^{3}$ Nurcholish Madjid, Islam Agama Kemanusiaan, Membangun Tradisi dan Visi Baru Islam Indonesia, $2^{\text {nd }}$ ed. (Jakarta: Paramadina, 2003), 203. atas pelanggaran-pelanggaran HAM dalam dunia pendidikan. Agar kajian lebih cermat, maka di sini digunakan pendekatan klasik, kultural, dan kritis atau disebut mix approach. ${ }^{4}$

\section{Prinsip Umum tentang HAM}

Dalam Teaching Human Rights yang diterbitkan Perserikatan Bangsa-bangsa (PBB) disebutkan, HAM merupakan hak yang ada pada setiap diri manusia sehingga tanpanya seseorang tidak bisa hidup sebagai seorang manusia. ${ }^{5}$ Misalnya, hak mendapatkan pendidikan. Hak ini merupakan klaim seseorang untuk mengembangkan diri atau dapat mengakses pendidikan. Akhirnya, tanpa adanya hak ini eksistensi seseorang yang berpendidikan tidak diakui.

Prinsip umum tentang HAM yang dicanangkan PBB pada 1948 dianggap sebagai pedoman standar bagi penegakan HAM bagi Negara-negara di dunia, yang disebut dengan Universal Declaration of Human Rights (UDHR). HAM bukan karena diberi oleh orang lain atau masyarakat, melainkan semata-mata berdasarkan atas martabatnya sebagai

4 Izzuddin Washil \& Ahmad Khoirul Fata, "HAM Islam dan DUHAM PBB: Sebuah Ikhtiar Mencari Titik Temu," MIQOT: Jurnal IlmuIlmu Keislaman 41, no. 2 (2018): 432-433, https://doi.org/10.30821/miqot. v41i2.394.

5 A. Ubaedillah \& Abdul Rozak, Demokrasi Hak Asasi Manusia dan Masyarakat Madani (Jakarta: ICCE UIN Syarif Hidayatullah, 2007), 252. 
manusia. ${ }^{6}$ Berikut ini beberapa prinsip tentang HAM yang berlandaskan pada UDHR:

1. Equality, yakni hak setara yang memiliki oleh setiap orang atau hak diperlakukan sama.

2. Non-discrimination. Artinya, jika semua orang dianggap setara, maka tidak ada diskriminasi. Jadi, diskriminasi merupakan kesenjangan akibat perlakuan yang seharusnya sama. $^{7}$

3. Interdependance. Jadi, apapun yang terjadi seseorang tetap akan disebut sebagai manusia dan memiliki hak asasi sebagai manusia.

4. Inalienable, yaitu hak yang tidak dapat dihilangkan, dipindahkan, dialihkan atau diganti dengan yang lain. Hak-hak asasi ini tidak dapat dicabut.

5. Indivisibility. Prinsip bahwa hak asasi tidak dapat dibagi, yakni melekat pada diri manusia, seperti hak sipil, politik, sosial, budaya, ekonomi, yang jika adanya pengabaian satu hak akan berdampak pada hak yang lain.

6. Universality, yakni hak asasi yang pada prinsip bersifat universal

${ }^{6}$ Jack Donnely, Universal Human Rights in Theory and Practice (Ithaca \& London: Cornell University Press, 2003), 7-21.

7 Jauhariah, Dinamika Hukum dan HAM (Jakarta: Penerbit Cintya Press, 2016), 79-80. yang dimiliki oleh setiap seorang, baik itu orang kulit putih, hitam, ataupun cokelat. Jadi, meskipun jenis kelamin, bahasa, budaya, dan bangsanya berbeda setiap orang tetap memiliki hak tersebut.

7. Human dignity. Prinsip ini menegaskan bahwa dalam hidup setiap orang harusnya menghormati hak orang lain dan menghargai martabat sesamanya.

PBB yang didirikan pada 1945 mengawal penegakan HAM agar tragedi kemanusiaan tidak terjadi kembali di masa depan. Oleh karena itu, mereka menyepakati gagasan universal HAM sebagai acuan bagi semua negara di dunia. Meskipun demikian, perjuangan HAM sebenarnya sudah dimulai sejak peradaban umat manusia sebelum masehi. Misalnya, muncul kitab Hamurabi (Babilonia) pada 4000 SM, Kekaisaran Romawi dan Yunani yang memberikan hak asasi pada kelompok atau kelas tertentu, kebijakan dari Raja Cyus dari Persia sekitar 2500 SM yang berkaitan dengan pelarangan bagi setiap orang untuk memaksa memeluk agama tertentu. Dalam Islam HAM sudah dimulai sekitar abad ke-7 M. Rasulullah Saw. telah mengajarkan hak asasi tidak sekadara kepada kaum muslim, tetapi juga kepada seluruh manusia melalui berbagai peristiwa antara lain seperti Khutbah Wada', Perjajian Khudibiyah, dan Piagam Madinah. 
Begitu juga perjuangan penegakan HAM di Barat, terutama di Inggris, Amerika Serikat, dan Prancis. Perjuangan panjang HAM di Inggris setidaknya ditandai oleh dua dokumen yang fenomenal: Magna Charta Libertatum (1215) dan Bill of Rights (1689). Magna Charta berisi kesepakatan bahwa hak rakyat didasarkan pada hukum agar tidak terjadi kesewenang-wenangan. Sedangkan Bill of Rights lahir akibat revolusi Inggris. HAM di negara Amerika Serikat dan Prancis tidak lepas dari Deklarasi Kemerdekaan Amerika (1776) - yang mengandung gagasan pemikir Prancis seperti John Locke, Montesquieu, dan J.J. Rosseau-dan Bill of Rights (1791) sebagai referensi formal terhadap kebebasan individu dalam hidup bernegara. Terakhir, konsepsi HAM ala Roosevelt yang memuat empat hak: freedom of speech, religion, fear, dan want. ${ }^{8}$ Di Prancis deklarasi HAM tertuang dalam Declaration of the Rights of Man the Citizen yang mejadi dasar terjadinya Revolusi Perancis.

Beberapa peristiwa penting di atas membuat PBB mendeklarasikan HAM pada 1948 dalam Universal Declaration of Human Rights atau Deklarasi Universal Hak Asasi Manusia (DUHAM); kemudian ditegaskan dengan Deklarasi Kairo oleh Organisasi Konferensi Islam

${ }^{8}$ Abdul Khakim, "Hak Asasi Manusia dalam Perspektif Pendidikan Islam," Journal Evaluasi 2, no. 1 (2018): 376, https://doi. org/10.32478/ evaluasi.v2i1.84.
(OKI) pada tahun 1990. Pada dasarnya DUHAM dan Deklarasi Kairo memiliki visi yang sama terhadap kemanusiaan baik di Barat maupun di dunia Islam. Hal ini tampak adanya kesamaan dalam beberapa pasal yang tertera di dalamnya.

Meski demikian, terdapat beberapa perbedaan seperti, pertama, pandangan dunia HAM di Barat bermuara pada kepentingan manusia sendiri (antroposentris dan individualistik), sedangkan HAM Islam merujuk pada tauhid (teosentris). Karena itu, kedua, sumber HAM Barat berasal dari filsafat, sementara HAM Islam bersumber dari al-Qur'an dan Sunnah. Implikasinya, ketiga, terdapat perbedaan dalam prinsip moralnya dengan batasannya masing-masing.

\section{Konsepsi HAM dalam Pendidi- kan Barat dan Islam}

Perumusan HAM dalam Islam didasarkan al-Qur'an dan Sunnah Nabi Saw. Di dalam al-Qur'an disinggung antara lain hak untuk hidup (QS. alIsrâ' [17]: 33, QS. al-An'âm [6]: 151), hak perlindungan kehormatan (QS. alHujurât [49]: 11-12), hak aman (QS. al-Nûr [24]: 27), hak kemerdekaan (QS. al-Hujurât [49]: 6), hak perlindungan dari kekerasan (QS. al-Anâm [6]: 164), hak berekspresi (QS. al-Taubah [9]: 71), hak beragama (QS. al-Baqarah [2]: 256, QS. al-Kâfirûn [109]: 6), hak berserikat (QS. Ali 'Imrân [3]: 104-105), hak sama 
di depan hukum (QS. al-Nisâ’ [4]: 58), hak memperoleh keadilan (QS. al-Syûrâ [42]: 15), hak memperoleh keperluan hidup (QS. al-Dzâriyah [51]: 19), hak memperoleh pendidikan (QS. Yûnus/10: 101), kesetaraan gender (QS. al-Baqarah [2]: 228), hak berkeluarga (QS. al-Nûr [24]: 32, QS. al-Mumtahinah [60]: 9).

Perihal ini Gus Dur menyebut 14 hak asasi yang disebutkan di dalam al-Qur'an: 1) hak untuk hidup, 2) hak untuk memperoleh keadilan, 3) hak untuk mendapat perlakuan yang sama, 4) hak untuk berpartisipasi dalam kehidupan sosial dan negara, 5) hak untuk menolak sesuatu yang melanggar hukum, 6) hak untuk memperoleh kemerdekaan, 7) hak untuk memperoleh kebebasan dari ancaman dan penuntutan, 8) hak untuk berbicara, 9) hak atas perlindungan terhadap penuntutan, 10) hak memperoleh ketenangan pribadi, 11) hak ekonomi termasuk hak mendapat upah yang layak, 12) hak untuk melindungi kehormatan dan nama baik, 13) hak atas harta benda, dan 14) hak untuk penggantian kerugian yang sepadan. ${ }^{9}$

Sedangkan di antara pengalaman Nabi dalam memimpin Madinah yang tertuang dalam Piagam Madinah dapat menjadi acuan dasar HAM. Di dalam piagam ini disepakati bahwa semua penduduk Madinah yang berasal dari

9 Abdurrahman Wahid, Muslim di tengah Pergumulan (Jakarta: LEPPENAS, 1983), 94. beragam suku dan agama patuh terhadap aturan seperti menjalin hubungan bertetangga dengan baik dan membela pihak yang teraniaya, saling membantu dalam menghadapi musuh bersama, saling menasihati, dan menghormati kebebasan beragama. ${ }^{10}$

Tidak hanya itu, pada akhir kenabian yakni pada peristiwa Haji Wada' di hadapan 100.000 orang lebih, Nabi Muhammad Saw. seperti mendeklarasi HAM pertama di dunia Islam.

Beliau memulai khutbahnya, "Katakan kepada mereka bahwa Rasulullah berkata, 'Tahukah kalian, bulan apa ini?' Mereka menjawab, “Bulan haram!” Nabi melanjutkan, "Katakan kepada mereka, 'Sesungguhnya Allah telah mengharamkan darah dan hartamu hingga kamu sekalian menemui Tuhanmu sebagaimana keharaman bulan kalian ini.' Dengan cara yang sama, Nabi melanjutkan, "Ayyuhâ al-nâs, tahukah kalian, negeri apa ini?" "Negeri haram!" jawab mereka. "Sesungguhnya Allah telah mengharamkan darah serta harta kalian hingga kalian menemui Tuhan kalian sebagaimana diharamkannya negeri kalian ini." "Ayyuhâ al-nâs, tahukah kalian, hari apa ini?" "Hari haji akbar!" jawab mereka. "Sesungguh-

${ }^{10}$ Muhammad Iqbal, Fiqh Siyasah Kontekstualisasi Doktrin Politik Islam (Jakarta: Prenada Media Grup, 2015), 37-39. 
nya Allah telah mengharamkan darah dan harta kalian hingga kalian menemui Tuhan kalian sebagaimana keharaman hari kalian ini ..." "Ammâ ba'du, ayyuhâ al-nâs, sesungguhnya istri-istrimu mempunyai hak atas dirimu, dan kamu memiliki hak pula atas diri mereka. Hendaknya kamu sekali-kali tidak mencampuri mereka secara paksa, dan hendaknya mereka sekali-kali tidak melakukan perbuatan jahat yang nyata ... kamu mengambil mereka (sebagai istri-istrimu) berdasarkan amanat Allah, dan halal bagimu mencampuri mereka berdasarkan kalimat-Nya..." "Ayyuhâ al-nâs, camkanlah ucapanku. Sebab sesungguhnya aku telah menyampaikan itu kepadamu. Perhatikan dan ketahuilah bahwa seorang Muslim itu saudara bagi Muslim lainnya, dan sesungguhnya kaum Muslim itu saling bersaudara. Tidak dihalalkan bagi seorang Muslim untuk merampas hak saudaranya sesama Muslim, kecuali apa yang diberikan kepadanya secara rela. Karena itu, janganlah kamu menganiaya dirimu sendiri." Lalu beliau menatap langit, dan bertanya, "Ya Allah, bukankah aku telah menyampaikannya kepada mereka?" Pertanyaan ini diulang oleh Rabi'ah dengan suara keras dan ditujukan kepada seluruh hadirin. Serempak 100.000 lebih orang yang terce- kam keharuan menjawab, "Benar, engkau telah menyampaikannya.” Kemudian sekali lagi Nabi menatap langit lalu berkata, "Ya Allah, saksikanlah." 11

Hal di atas juga sejalan dengan konsep Islam khususnya prinsip Tauhid karena berdampak pada daya pembebasan diri (self-liberation) sekaligus sosial, seperti bahwa semua manusia sama di hadapan Tuhan yang membedakannya hanya ketakwaannya (egalitarianisme). Sebagai khalifah Tuhan di bumi, manusia juga harus menegakkan hak asasi tersebut dengan bertanggung jawab. Dengan demikian, dalam penerapan hak asasi tersebut hurus dibarengi dengan kewajiban asasi. ${ }^{12}$

\section{Implementasi HAM dalam Pen- didikan}

Pada dasarnya penerapan HAM tidak dapat dipisahkan dengan bidang pendidikan. Pendidikan merupakan proses pembentukan manusia dan nilainilai kemanusiaan. Oleh karena itu, semua manusia di muka bumi berhak mendapatkan proses tersebut tanpa

11 Ali Syariati, Rasulullah Saw. Sejak Hijrah Hingga Wafat: Tinjauan Kritis Sejarah Nabi Periode Madinah, trans. by Afif Muhammad, $2^{\text {nd }}$ edition (Bandung: Pustaka Hidayah, 1995), 109-112.

12 Mashood A. Baderin, International Human Rights and Islamic Law (New York: Oxford University Press, 2003), 13. 
membeda-bedakan latar belakangnya. Karena itu pula terdapat prinsip kesetaraan dalam lembaga pendidikan, baik peserta didik maupun pendidik memiliki hak yang sama dalam hal ilmu.

Selain itu, hak untuk memperoleh pendidikan setiap warga Negara juga dijamin dalam konstitusi UUD 1945 Pasal 31 sebagai berikut:

1. Setiap warga negara berhak mendapat pendidikan;

2. Setiap warga negara wajib mengikuti pendidikan dasar dan pemerintah wajib membiayainya;

3. Pemerintah mengusahakan penyelenggaraan satu sistem pendidikan nasional yang meningkatkan keimanan dan ketakwaan serta akhlak mulia dalam rangka mencerdaskan kehidupan bangsa yang diatur oleh undang-undang;

4. Negara memprioritaskan anggaran pendidikan sekurang-kurangnya $20 \%$ dari anggaran pendapatan dan belanja negara, juga anggaran pendapatan dan belanja daerah untuk memenuhi kebutuhan penyelenggaraan pendidikan nasional;

5. Pemerintah memajukan ilmu pengetahuan dan teknologi dengan menjunjung tinggi nilai-nilai agama dan persatuan bangsa untuk kemajuan peradaban serta kesejahteraan umat manusia.

\section{Simpulan}

Urian tersebut di atas, dapat ditarik simpulan bahwa HAM melekat sejak pada diri manusia lahir sebagai anugerah Tuhan yang Maha Pencipta kepada manusia. Kadang di kalangan masyarakat luas, kesadaran tentang HAM masih belum disadari secara menyeluruh. Oleh karena itu, HAM penting untuk dijadikan sebagai pengetahuan agar ditransfer ke dalam dunia pendidikan. Hal ini bertujuan supaya setiap orang mengetahui hak mereka sendiri, baik dalam hidup, berbangsa, dan bernegara. Dengan mengkaji deklarasi DUHAM oleh negara-negara dunia internasional melalui PBB dan Deklarasi Kairo yang dilakukan oleh OKI, dapat diketahui bahwa pengetahuan riil tentang HAM dalam kehidupan manusia Barat dan Islam sehingga mengetahui batasan dan nilai-nilai moral yang terkandung di dalamnya. Dalam pendidikan HAM sangat bermanfaat sebagai sebuah pijakan yang dapat mengantarkan generasi masa depan menjalani kehidupan baik sebagai individu dan kelompok masyarakat. 


\section{Daftar Pustaka}

Baderin, Mashood A. International Human Rights and Islamic Law. New York: Oxford University Press, 2003.

Donnely, Jack. Universal Human Rights in Theory and Practice. Ithaca \& London: Cornell University Press, 2003.

Iqbal, Muhammad. Fiqh Siyasah Kontekstualisasi Doktrin Politik Islam. Jakarta: Prenada Media, 2015.

Jauhariah. Dinamika Hukum \& HAM. Jakarta: Penerbit Cintya Press, 2016.

Khakim, Abdul. "Hak Asasi Manusia dalam Perspektif Pendidikan Islam." Journal Evaluasi 2, no. 1 (2018). https://doi.org/10.32478/ evaluasi.v2i1.84.

Khaliq, Farid Abdul. Fiqih Politik Islam, translated by Faturrahman A. Hamid. Jakarta: Amzah, 2005.

Kristiawan, Muhammad. Filsafat Pendidikan: The Choice Is Yours. Yogyakarta: Valia Pustaka, 2016.

Madjid, Nurcholish. Islam Agama Kemanusiaan, Membangun Tradisi dan Visi Baru Islam Indonesia. $2^{\text {nd }}$ edition. Jakarta: Paramadina, 2003.

Syariati, Ali. Rasulullah Saw. Sejak Hijrah Hingga Wafat: Tinjauan Kritis Sejarah Nabi Periode Madinah, translated by Afif Muhammad. $2^{\text {nd }}$ edition. Bandung: Pustaka Hidayah, 1995.

Ubaedillah, A. \& Abdul Rozak. Demokrasi Hak Asasi Manusia dan Masyarakat Madani. Jakarta: ICCE UIN Syarif Hidayatullah, 2007.

Wahid, Abdurrahman. Muslim di tengah Pergumulan. Jakarta: LEPPENAS, 1983.

Washil, Izzuddin, and Ahmad Khoirul Fata. "HAM Islam dan DUHAM PBB: Sebuah Ikhtiar Mencari Titik Temu." MIQOT: Jurnal IlmuIlmu Keislaman 41, no. 2 (2018). https://doi.org/10.30821/miqot. v41i2.394. 